\title{
Impact Analysis of System Support toward Computer Self-Efficacy and Effectiveness of User Performance
}

\author{
(Case Study: E-Learning Applications)
}

\author{
Arista Pratama ${ }^{1}$, Tri Lathif Mardi ${ }^{2}$, Siti Mukaromah ${ }^{3}$ \\ Department of Information System \\ Universitas Pembangunan Nasional "Veteran" Jawa Timur \\ Surabaya, Indonesia \\ 12aristapratama.si@upnjatim.ac.id, ${ }^{2}$ trilathif.si@upnjatim.ac.id, ${ }^{3}$ sitimukaromah.si@upnjatim.ac.id
}

\begin{abstract}
Humans create systems that must support human achievement in the use of new application technologies to the user capabilities, and characteristics of the technology can be used optimally for the accomplishment of objectives. Availability of a support system is recognized as an essential aspect which affects the level of computer self-efficacy of someone in the use of technology. Computer self-efficacy has a role in the decision to use the technology and make it easier to process skills that are related to the effectiveness of the use of technology. This study aims to determine the impact of system support on the level of computer self-efficacy to improve the efficacy in the use of new application technologies. The result of this study provide that the system supports significant and impact positively on the level of computer self-efficacy and effectiveness in the use of new application technologies. The results of the study can be used as an additional reference for software developers to focus on developing functions of assistance and computer simulations to improve self-efficacy and effectiveness in the use of new applications. Development system support is expected to help to optimize the resources (time, money, and human).
\end{abstract}

\section{Keywords-system support; computer self-efficacy; effectiveness}

\section{INTRODUCTION}

The development of information technology has led to a major change in the development of application technology that is further expected to help individuals in various aspects of their life. Humans as users of application technology play an important role in determining the success of a new application technology. Consequently, when human competence and behavior do not support the utilization of application technology, its usage will fail. In line with this, effectiveness is the basis for achieving success in the use of new application technologies. The use of a new application technology is considered to be effective if the new application can provide results that are in accordance with the initial goals that have been set. The effectiveness of application technology use is affected by the level of the individual's computer selfefficacy. Research findings have showed that computer selfefficacy plays an essential role in the decision of the system use and it helps to process skills related to the effectiveness of computer use [1].
Computer Self-Efficacy (CSE) is an individual's belief in their ability to be competent in using technology [2]. Selfefficacy derives from the Theory of Behavioral Change (TBC) [3], which is defined as a self-perception of the ability to achieve a particular activity [4]. Computer self-efficacy has to deal with judgments of an individual's ability to use a computer. These considerations include choices about doing behavior, effort and persistence to deal with obstacles in achieving the performance of behavior related to the use of technology [5]. Computer self-efficacy is believed to influence emotional responses from individuals. Each will tend to like and enjoy the behaviors that are perceived to be done well. Computer self-efficacy has a vital role in shaping feelings including anxiety and individual behavior. Their research findings revealed that each with high self-efficacy would take more pleasure and experience less anxiety in using a computer [2]. Hence, affection and anxiety have a significant influence on computer use.

High support from the organization would reduce selfefficacy considerations [2]. If each individual are able to call someone at any time to help when facing difficulties, then the individual may never be forced to do so for himself and will continue to believe that he is unable to do so. For example, computer users face computing problems and call a technician to fix them. If the problem can be fixed by a technician not by the user, it will not be surprising if the user will begin to doubt his ability. When this happens, this case will be a problem in providing support [5]. To overcome this problem, technicians who provide support should also help improve users' selfefficacy, such as by explaining how problems can arise and describing the support available on a system (system support) as an aid to solving problems appear. Therefore, when the problems re-occur, users can use the support available on a system (system support) to help them to solve these problems.

The support system plays a role in controlling the interaction of potential users so that the user's technical capabilities and system characteristics can be used optimally for achieving goals. System support is defined as assistance/instructions in digital form for computer-based learning and task-oriented [6]. The help function (for example, availability of keyword search, search index, and context 
assistance sensitivity) has a positive impact on interface design. System support was divided into tutorials, documentation, and assistance functions [6]. System support consists of; drill and practice, tutorial, simulation, instructional game, and problem-solving [7]. Based on these literatures, this present study only uses a portion of the grouping of support systems which include; tutorials (conceptualized with text \& images), simulations (conceptualized with pictures \& sounds), and help functions (conceptualized with context-sensitive instructions). The availability of a support system is recognized as an important aspect that influences a person's computer self-efficacy level in the use of technology [3].

Referring back to the background of the study described above, the purposes of this present study are; 1) to determine the role and importance of system support on the level of computer self-efficacy of users in learning the use of new technologies, 2) to determine the effect of computer selfefficacy on effectiveness in the use of new technologies. Researchers used a quantitative approach with the support of existing literature to be able to explore the topic of this present study in more detail.

\section{STUDY OF LITERATURE}

\section{A. System Support}

System Support is defined as support/assistance in digital form for computer-based learning and oriented to the tasks available on a system. System support has the role of controlling and interacting with users in the process of learning new technologies to change the technical ability of prospective users to achieve goals and complete tasks [6]. System support was divided into tutorials, documentation, and help [6]. System support consists of; drill and practice, tutorial, simulation, instructional game, and problem-solving [7]. Based on these literatures, this study only uses a portion of the grouping of support systems which include tutorial, simulation, and help-function.

\section{B. Computer Self-Efficacy}

Computer Self-Efficacy (CSE) is an individual's belief in their ability to be competent in using technology [2]. Selfefficacy derives from the Theory of Behavioral Change (TBC) [3] which defines it as a self-perception of the ability to achieve an activity [4]. Computer self-efficacy is related to judgments of an individual's ability to use a computer. These considerations include choices about doing behavior, effort and persistence to deal with obstacles in achieving the performance of behavior related to the use of technology [5].

Computer self-efficacy has three dimensions related aspects, namely magnitude, strength, and generalizability [3]. Magnitude is related to reflecting the level of ability (e.g. easy, medium, difficult) that is expected in performing computer tasks [8]. The link relates to the level of confidence or belief in a consideration (eg not sure-sure) that someone has about the ability to perform various computational tasks [8]. Generalizability relates to how far judgment (judgment) in a particular computational domain activity [9].

\section{Effectiveness}

Effectiveness is defined as the degree of success in aiming the desired target. Effectiveness is also called effective, if the goals or targets have been achieved. In line with this definition, the same opinion was also expressed by Caster I. Bernard who defines effectiveness as the achievement of goals that have been agreed upon [10]. Alongside this, the effectiveness indicator is the achievement of a predetermined goal or goal is a measurement in which a target has been achieved by what has been planned. Effectiveness focuses on outcomes, programs, or activities that are considered sufficient if the output produced can meet the expected objectives. Dealing with this matter, the effectiveness is described as the entire cycle of input, process, and output that refers to results.

The level of success used in this present study is an indicator of the completeness of learning outcomes and satisfaction. Achievement is the level of ability a person has in receiving information obtained in a learning process that involves cognitive (knowledge), affective (attitude), and psychomotor (skills) aspects. Satisfaction is a feeling of satisfaction from an activity such as information seeking. Someone emotionally will feel satisfied if the experience in using the system or website in line with the needs, expectations, and goals to be achieved.

\section{METHOD}

Fit model test analysis was conducted to achieve the research objectives. Therefore, this present study was conducted using a causality, descriptive, and quantitative approach. This study is considered causality because it aims to determine the effect of the relationship between variables on the conceptual model. This study is seen as a descriptive study because it aims to explain the influence between variables in the model by testing the hypothesis. In this present study, a quantitative approach was registered by calculating and analyzing data obtained from surveys and interview questionnaires.

\section{A. Research Data Collection}

This study used convenience sampling technique. Convenience sampling is a sampling procedure that selects a sample from the person or unit that is most easily found or accessed. Although using convenience sampling, this research still prioritizes the achievement of research objectives related to the influence of the availability of computer self-efficacy and effectiveness level support systems. The present study used two groups of respondents, namely the group support system respondents (tutorials, simulations, assistance functions) and groups of respondents without system support involving 160 students. The study used e-learning applications as new application technology objects. To achieve the goals of the study, the selection of respondents considered several criteria, like the following:

- Respondents involved in the study have the same level of knowledge, those who have never used e-learning 
- Respondents engaged in the study have the same level of education

- Respondents get system support.

\section{B. Data Analysis}

This study used quantitative methods by analyzing data using Structural Equation Modeling (SEM). Researchers used SEM (Structural Equation Modeling) because SEM can be used to analyze multivariate variables or the use of nominal / ratio scales. This study used latent variables that cannot be measured directly. For example, system support variables. System support variables cannot be measured directly. Therefore, the researcher must use several indicators or questionnaires. SEM (Structural Equation Modeling) can be used for complex research and SEM can do factor analysis, regression analysis and path analysis simultaneously. Data obtained from the questionnaire were analyzed using quantitative data analysis techniques, called descriptive analysis and inferential analysis. Descriptive analysis is used to analyze data by describing the data. In this study, SPSS statistical software version 17 was registered. Inferential analysis was used to analyze sample data against the applicable population. In inferential analysis research, SmartPLS software was used.

\section{Hypothesis in This Study}

System Support is defined as support/assistance in digital form for computer-based learning and oriented to the tasks available on a system. System support has the role of controlling and interacting users in the process of learning new technologies to change the technical ability of prospective users to achieve goals and complete tasks [6]. With the availability of a support system, it is believed that it can affect a person's computer self-efficacy level in the use of technology [7]. Based on the above theories, a hypothesis is formulated:

\section{H1 : System support can increase the user's computer self- efficacy}

Computer Self-Efficacy (CSE) is an individual's belief in their ability to be competent in using technology [2]. Computer Self-Efficacy (CSE) is a determining factor for the success of the application of information systems for it has been proven to have an essential role in shaping feelings (affects) including anxiety and individual behaviors, enhancing personal competence [4], technology use performance [11] [4], as well as improving attitudes and beliefs in technology [4]. According to the above theories, further hypothesis is formulated:

H2 : Computer self-efficacy affects the effectiveness in the use of technology.

\section{RESULT}

The hypothesis in this present study was examined by Partial Least Square analysis using SmartPLS 2.0 software. The stages of analysis carried out in this present study including evaluation of the measurement model (outer model) and evaluation of the structural model (inner model).

The first evaluations on the outer model were convergent validity and discriminant validity. The indicator is considered to meet the convergent validity when it has the value of the outer loading and AVE respectively above 0.5. Alongside this, an indicator is said to meet the discriminant validity if the value of the indicator loading towards its variable in the crossloading table is the largest when compared to other variables in the model.

TABLE I. CONVERGENT VALIDITY

\begin{tabular}{|c|c|c|}
\hline Indicator & Outer Loading & \multirow{2}{*}{ AVE } \\
\cline { 1 - 2 } SS1 & 0.781 & \multirow{2}{*}{0.668} \\
\cline { 1 - 2 } SS2 & 0.835 & \\
\hline SS3 & 0.807 & \\
\hline SS4 & 0.801 & \multirow{2}{*}{0.822} \\
\cline { 1 - 2 } SS5 & 0.837 & \\
\hline SS6 & 0.840 & \multirow{2}{*}{0.772} \\
\hline Strenght & 0.708 & \\
\hline Magnitude & 0.850 & \\
\cline { 1 - 2 } Generalizability & 0.775 & \\
\cline { 1 - 2 } Satisfaction & 0.928 & \\
\cline { 1 - 2 } Achievement & 0.827 & \\
\cline { 1 - 2 } & &
\end{tabular}

Table 1 shows that the indicators in each System Support, IT Self-Efficacy, and Effectiveness variable had the value of outer loading above 0.5 . In addition to this, the AVE value produced was also above 0.5 . Therefore, it can be said that these indicators had met the criteria of the convergent validity.

As table 2 points out, each indicator had the highest outer loading on each variable that was measured when compared to other variables. These results indicated that discriminant validity had also been fulfilled.

The final evaluation of the outer model was reliability. In line with this, composite reliability tests the reliability values of the indicators in a particular construct (variable). A construct or variable is said to meet reliability if it has a composite reliability value $>0.7$.

TABLE II. DISCRIMINANT VALIDITY

\begin{tabular}{|l|c|c|c|}
\hline \multicolumn{1}{|c|}{ Indicator } & System Support & IT Self-Efficacy & Effectiveness \\
\hline SS1 & 0.781 & 0.148 & 0.289 \\
\hline SS2 & 0.835 & 0.329 & 0.330 \\
\hline SS3 & 0.807 & 0.334 & 0.252 \\
\hline SS4 & 0.801 & 0.387 & 0.356 \\
\hline SS5 & 0.837 & 0.259 & 0.276 \\
\hline SS6 & 0.840 & 0.365 & 0.413 \\
\hline Strenght & 0.285 & 0.708 & 0.346 \\
\hline Magnitude & 0.299 & 0.850 & 0.365 \\
\hline Generalizabilit & 0.337 & 0.775 & 0.384 \\
y & 0.407 & 0.482 & 0.928 \\
\hline Satisfaction & 0.273 & 0.319 & 0.827 \\
\hline Achievement & & & \\
\hline
\end{tabular}

Table 3 indicates that the composite reliability value of each research variable was more than 0.7 . It can be concluded that each variable had good reliability. 
The next evaluation conducted was an evaluation of the structural model (inner model). This evaluation will explain the value of R-Square, Q-Square, GOF, and hypothesis testing through the t-statistics value.

TABLE III. COMPOSITE RELIABILITY

\begin{tabular}{|l|c|}
\hline \multicolumn{1}{|c|}{ Variabel } & Composite Reliability \\
\hline System Support & 0.923 \\
\hline IT Self-Efficacy & 0.822 \\
\hline Effectiveness & 0.871 \\
\hline
\end{tabular}

TABLE IV. R-SQUARE DAN Q-SQUARE

\begin{tabular}{|l|c|c|c|}
\hline \multicolumn{1}{|c|}{ Variabel } & $\boldsymbol{R}$-Square & Q-Square & GOF \\
\hline IT Self-Efficacy & 0.157 & \multirow{2}{*}{0.343} & 0.359 \\
\hline Effectiveness & 0.221 & & \\
\hline
\end{tabular}

The R-Square value generated on the IT Self Efficacy variable was 0.157 , indicating that the existence of a System Support could affect $15.7 \%$ IT Self Efficacy from system users. With the same interpretation, the $\mathrm{R}$ Square value generated in the Effectiveness variable was 0.221, indicating that IT Self Efficacy could affect $22.1 \%$ effectiveness of the system user. The Q-Square value was $0.343>0$, suggesting that the model has good predictive accuracy. GOF of $0.359>$ 0.3 is categorized as a fit model.

TABLE V. HyPOTHESIS TESTING

\begin{tabular}{|c|l|c|c|}
\hline \multicolumn{2}{|c|}{ Hypothesis } & Coefficient & t-Statistics \\
\hline 1 & $\begin{array}{l}\text { System Support } \rightarrow \text { IT Self } \\
\text { Efficacy }\end{array}$ & 0.396 & 4.936 \\
\hline 2 & $\begin{array}{l}\text { IT Self Efficacy } \rightarrow \\
\text { Effectiveness }\end{array}$ & 0.470 & 5.335 \\
\hline
\end{tabular}

The correlation coefficient of system support toward IT self-efficacy was 0.396 with a statistical $\mathrm{T}$ value of 4.936 (> 1.960) which met the requirements. Thus, it can be said that that system support variables have a positive and significant influence on IT self-efficacy. This result also indicated that system support has a strong influence in shaping trust in one's ability to use a new technology. The better the quality of the system support of a technology, the more easily it will be absorbed by the user so that it will create a self-confidence in using the technology. IT self-efficacy was also concluded to have a positive and significant effect on effectiveness, with a coefficient of 0.470 with a statistic value of 5,335 (> 1,960). This means that the better the user's IT self-efficacy towards a new technology, the higher the effectiveness of the technology use.

\section{DISCUSSION AND CONCLUSION}

\section{A. Discussion}

The results of the study prove that the formation of system support can improve computer self-efficacy [7]. The formation of a good support system can improve the user's computer self-efficacy for it helps each individual to solve problems related to technology use [5]. Moreover, by a good support system, the individual will be more confident in their ability to be able to complete independently.

Computer self-efficacy contributes to the effectiveness in the use of new application technologies [1] [11] [12]. Users who have a high level of computer self-efficacy will feel that their activities are more enjoyable and it can reduce the level of anxiety by using a computer. That way, it can increase the level of effectiveness in the use of new application technology.

The results of the study prove that the establishment of a system support can help to overcome cognitive limitations to reduce the possibility of user errors related to the use of new application technology. If user errors can be minimized, it can improve computer self-efficacy and effectiveness in the use of new application technologies.

\section{B. Conclusion}

The findings of this present study confirm that the system support in the form of simulation and assistance function has a positive and significant effect on computer self-efficacy. The establishment of a good support system can improve the user's computer self-efficacy for it help each individual to solve problems related to the use of new application technologies. By a good support system, each individual will be more confident in their ability to be able to complete the problems occur independently.

The results of this study also confirm that computer selfefficacy obtained from the system support in the form of simulation and assistance function has a positive and significant effect on the effectiveness in the use of new application technology. The higher the level of computer selfefficacy of users, the better the effectiveness of computer use. The results of this study can be used as an additional reference for software developers to focus more on developing assistance and simulation functions to improve computer selfefficacy and effectiveness in the use of new applications. The development of the aid function is expected to help to optimize the resources (time, money, and people) they have.

For future research, it is expected to involve more numbers of respondents across generations and education such as students, teachers, lecturers, etc. Therefore, the data obtained can be extracted more profoundly and a broader perspective to find out whether it will affect the results of the research will be gathered. Alongside this, future research is expected to be able to conduct a more in-depth analysis to be able to reveal additional factors that can affect the increase in computer selfefficacy and effectiveness, for instance: cognitive factors and external factors related to user aspects such as motivation, age, culture, etc.

\section{ACKNOWLEDGMENT}

The authors wish to thank the other member of the computer science faculty especially the information systems program in Universitas Pembangunan "Veteran" Jawa Timur for their help throughout this work. 


\section{REFERENCES}

[1] G.M. Marakas, Yi, Y. M., \& R.D. Johnson , "The Multilevel and Multifaceted Character of Computer Self-Efficacy Toward Clarification of the Construct and an Integrative Framework for Research," Inf. Sys. Res, vol 9 No.2, pp 126-163, 1998.

[2] D.R. Compeau, \& C.A. Higgins , "Computer Self-Efficacy: Development of a Measure and Initial Test," MIS Q., vol. 19, No. 2, 189-211, 1995.

[3] A. Bandura, "Self-Efficacy: The Exercise of Control, Freeman, New York," 1997.

[4] H.V. Kher, Downey, P. J., \& E. Monk, “A Longitudinal Examination of Computer Self-Efficacy Change Trajectories During Training," Comput. Hum. Behav. 29, pp 1816-1824, 2013.

[5] Jogiyanto, "Sistem Informasi Keperilakuan. Yogyakarta: Penerbit Andi," 2007.
[6] S.A. Selber, J. Johnson, \& B. Mechlenbacher, "Online Support System: Tutorials, Documentations, and Help," Comput. Sci. Eng., pp 16191643, 1997.

[7] A. Doering, \& G. Valetsianos, "Teaching with Instructional Software." Vol 73-108, 2009.

[8] L.M. Shortridge-Baggett, "The theory and measurement of the selfefficacy construct,", Res. Meas. Perspect., pp. 9-28, 2002.

[9] F. Lunenburg, "Self-efficacy in the workplace: implications for motivation and performance," Int. J. Manag., Bus, Adm. , vol 14(1), 2011.

[10] I. Benard, Chaster, "Organisasi dan Manajemen Struktur, Prilaku dan Proses,” Jakarta: Gramedia, 1992.

[11] D.R Compeau., C.A. Higgins, \& S. Huff , "Social Cognitive Theory and Individual Reactions to Computing Technology: A Longitudinal Study," MIS Q. , vol. 23, No. 2, 145-158, 1999.

[12] B. Zimmerman, J., "Self-Efficacy: An Essential Motive to Learn," Cont. Edu. Psychol., vol 25, 82-91, 2000. 